\title{
National Identity, Revolt and Taxation
}

\section{Chee Meng Tan, Vengadeshwaran Sarma}

Nottingham University Business School, University of Nottingham Malaysian Campus, Semenyih, Malaysia

Email:cheemeng.tan@nottingham.edu.my

How to cite this paper: Tan, C.M. and Sarma, V. (2018) National Identity, Revolt and Taxation. Theoretical Economics Letters, 8, 2972-2986.

https://doi.org/10.4236/tel.2018.814185

Received: August 2, 2018

Accepted: October 17, 2018

Published: October 20, 2018

Copyright () 2018 by authors and Scientific Research Publishing Inc. This work is licensed under the Creative Commons Attribution International License (CC BY 4.0).

http://creativecommons.org/licenses/by/4.0/

\begin{abstract}
This paper investigates the impact of national pride on the likelihood of revolt. We propose a sequential game with a representative rich agent who decides and implements the tax rate, and a representative poor agent who either launches a revolt to oust the rich or accepts income redistribution. Using the economics of identity, the poor's utility not only depends on agent income but on the utility from national identification. We demonstrate that the likelihood of revolt by the poor and the tax rate that the rich needs to implement to avert a revolt decreases with national pride. We substantiate these results using logit regression analysis applied to data in the World Value Survey.
\end{abstract}

\section{Keywords}

National Autocracy, National Identity, Taxation, Revolt

\section{Introduction}

History is replete with individuals and governments that use nationalism to consolidate power. A demagogue such as Hitler came into power under the guise of social nationalism, while contemporary non-democracies the likes of North Korea, Iran and Russia flaunt nationalistic credentials to consolidate regime legitimacy [1].

A plausible explanation why countries promote nationalism lies with the myth that denizens owe a duty to the state, which overrides all other obligations whether it be public or otherwise [2]. This suggests that non-democracies could potentially employ state-sponsored variants of nationalism as a cohesive force to strengthen their authority. Conversely, a lack of national identification or pride may undermine autocracies, such as the case of the Tunisian Arab Spring when, after the self-immolation of Mohamed Bouazizi, Tunisian youths who have long endured humiliation and disrespect under Ben Ali's regime overthrew the kleptocracy [3]. 
Owing to the importance of national identity in regime survivability, we develop a theoretical model in which poor citizens revolt or accept income redistribution from rich elites. The elites derive utility from income, but the poor are nationalists, which means that its utility depends on income elements of the nation that poor agents derive utility or disutility from. We demonstrate three main results. First, increasing national pride decreases the likelihood of revolt. Second, increasing national pride increases the likelihood that a revolt is never imminent. Third, national pride reduces the tax rate needed to avert a revolt. We substantiate the second and third result using logit analysis applied to data from the World Value Survey.

This paper is organized in the following manner. First, we discuss the literature review then present a theoretical model, which applies the economics of identity of Akerlof and Kranton [4] on the theory of political transitions by Acemoglu and Robinson [5]. We then proceed to derive some comparative statics and present propositions highlighting that increasing national identification decreases the likelihood of agent revolt. We subsequently discuss the empirical analysis, which uses logit regression analysis to support our theoretical findings. Finally, we conclude the paper.

\section{Literature Review}

To the best of my knowledge, no published work addresses the impact of national identification on agent's preference for revolt at the empirically and theoretically. As a result, there is insufficient amount of research dedicated to addressing the impact of national identity on agent's revolutionary tendencies.

This paper contributes to several strands of the political science and economy literature. The first relates to the methods non-democracies use to maintain power. Representative works include Wintrobe [6] [7] detailing how dictators use repression and rent distribution to supporters to consolidate power, and $\mathrm{Pa}$ dró i Miquel (2007) that shows dictators allocate rents to their own ethnic and religious groups to secure support. More recently, Alesina and Reich [8] theorizes states use nationalism to avoid democratization. One result our paper demonstrates is that increasing national pride decreases the likelihood of revolts, which consolidates non-democracies.

The second relates to state motivation for promoting nationalism. Gellner [9] theorizes that governments promoted nation-building during the industrial revolution to facilitate better communication in markets, while Lott [10] finds that totalitarian regimes are more likely to invest substantially in public education to indoctrinate children compared to democracies. Kymlicka [11] argues that trust built through nationalism exhorts citizens to sacrifice themselves for the nation. Our paper, however, shows that citizens may forgo higher income distribution to avoid undermining national status, which substantiates Lymlicka's argument that citizens may forgo self-interest for the sake of national interest. 
The third is the theory of political transition. Important scholarly pieces include Acemoglu and Robinson [5], which analyze game theoretically why revolts occur in non-democracies, and Acemoglu, Ticchi, and Vindigni [12] which extends Acemoglu and Robinson's earlier work by demonstrating that insufficient concessions to the military may cause the emergence of a military dictatorship. While the aforementioned works are rooted in economic causes, we contribute to this literature by showing that higher national identification decreases the tax rate required to avert a revolt, which increases the likelihood that redistribution occurs and decreases the probability that revolutions take place.

\section{Model}

We consider a sequential game with complete information following Acemoglu and Robinson [5], where a non-democracy is populated by identical rich agents who set the tax rate and identical poor agents who either revolt or accept income redistribution. The proportion of rich and poor citizens is $\delta$ and $1-\delta$, but the elites are the minority $(\delta<1 / 2)$. The average income of the nation is $\bar{y}$, and the proportion of income held by citizens is $1-\theta$ and the elites is $\theta$. Hence, the an elite's income is

$$
y_{r}=\frac{\theta}{\delta} \bar{y}
$$

and each citizen is

$$
y_{p}=\frac{1-\theta}{1-\delta} \bar{y}
$$

The timing of events is as follows:

1) Nature reveals the cost of revolt $\mu \sim[0,1]$, which is the proportion of income destroyed after a revolt occurs.

2) The rich sets a flat tax $\tau$ that is distortionary with deadweight lost $\tau^{2} / 2$.

3) The poor either launches a revolution or accepts income redistribution.

a) If the poor revolts, it will always win since they have de facto power as the majority. Subsequently, the elites are disenfranchised with zero income and the poor shares the remaining income equally among its members.

b) If the poor accepts redistribution, the rich remains in power and implement tax $\tau$.

4) Consumption Takes Place and the Game Ends

Formally, the action of the rich is $\omega_{r}=\{\tau\}$ and that of the poor is $\omega_{p}=\{\rho(\tau)\}$, where $\rho=1$ denotes revolution and $\rho=0$ denotes no revolution. The game is illustrated in Figure 1 and we define the equilibrium of the game below.

Definition 1 The equilibrium of the game in Figure 1 is a subgame perfect equilibrium where the strategy combination $\left\{\tilde{\omega}_{p}, \tilde{\omega}_{r}\right\}$ are best responses to each other in every proper subgame. 


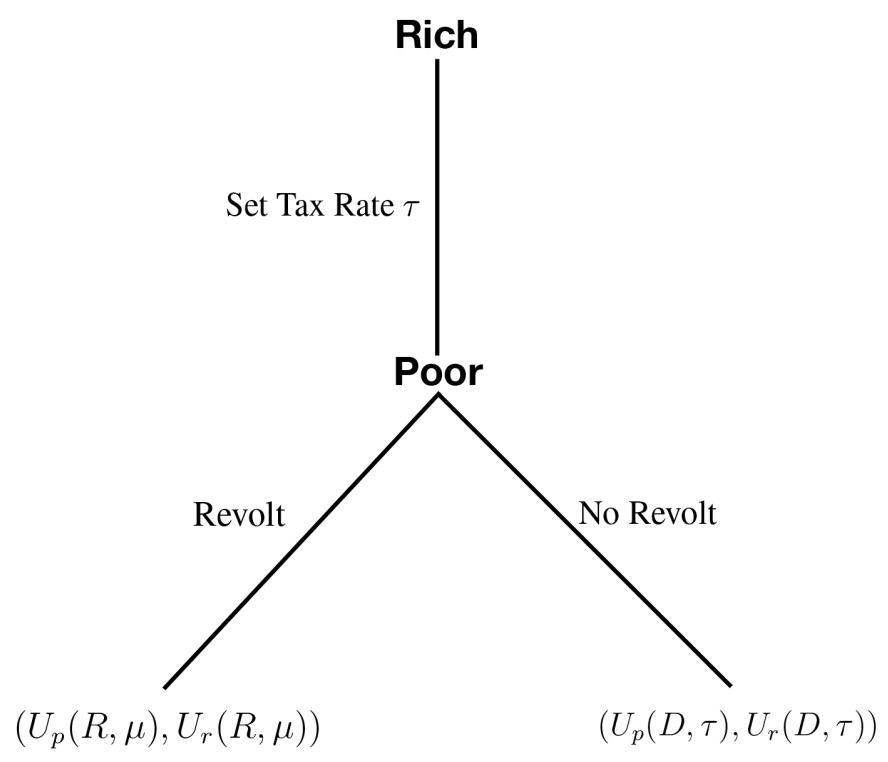

Figure 1.Tree diagram of the game. $U_{p}(R, \mu)$ and $U_{r}(R, \mu)$ denote the poor and rich's post-revolt utility, while $U_{p}(D, \tau)$ and $U_{r}(D, \tau)$ denote the poor and rich's post-tax utility.

Let $S=D$ denote the state in which income redistribution occurs. The income of an agent $i \in\{p, r\}$ is

$$
\pi_{i}(D, \tau)=(1-\tau) y_{i}+\left(\tau-\frac{\tau^{2}}{2}\right) \bar{y}
$$

following Bolton and Roland [13]. We assume that rich elites are only concerned with material payoff, hence the post-tax utility of the rich is equal to its income

$$
U_{r}(D, \tau)=(1-\tau) y_{i}+\left(\tau-\frac{\tau^{2}}{2}\right) \bar{y}
$$

Unlike the rich, we assume that the poor "cares" for the nation, which means that the poor's utility depends on national identification. We model the poor's utility using the economics of identity from Akerlof and Kranton [4], which state that individuals not only derive utility from income, but also from social group identification. Following Shayo [14], Sambanis and Shayo [5], and Tan, Lee and $\mathrm{Ng}$ [16], the post-tax utility of a citizen is

$$
U_{p}(D, \tau)=\pi_{p}(D, \tau)+\sigma\left[h_{\sigma}+\bar{\pi}(D, \tau)\right]-w\left\{h_{w}+\left|\pi_{p}(D, \tau)-\bar{\pi}(D, \tau)\right|\right\}
$$

The middle term gauges the utility agents derive from national identification, and the coefficient $\sigma \in[0,1]$ measures citizen saliency towards negative national attributes. We interpret this coefficient as the degree of "pride" agents have towards positive attributes of the nation, such as exogenous parameter $h_{\sigma}>0$, which may represent such national elements as art, history, culture and national sports teams winning in international tournaments, and the nation's post-tax average income 


$$
\bar{\pi}(D, \tau)=\left(1-\tau^{2} / 2\right) \bar{y}
$$

The third term in (5) gauges the poor's disutility. The coefficient $w \in[0,1]$ measures agent saliency towards national attributes that bring agent disutility, which is summarized by the parameter $h_{w}>0$ for national attributes unrelated to material payoff (such as the degree of ethnolinguistic fractionalization) and the income disparity between the poor and the national average. Substituting (4) and (6) into (5), the poor's post-tax utility is

$$
\begin{aligned}
U_{p}(D, \tau)= & (1-\tau) \frac{1-\theta}{1-\delta} \bar{y}+\left(\tau-\frac{\tau^{2}}{2}\right) \bar{y}+\sigma\left\{h_{\sigma}+\left(1-\frac{\tau^{2}}{2}\right) \bar{y}\right\} \\
& -w\left\{h_{w}+(1-\tau) \frac{\theta-\delta}{1-\delta} \bar{y}\right\}
\end{aligned}
$$

Note that the most preferred tax rate of the poor $\tau_{m}$ that maximizes the poor's post-tax utility is obtained by taking the first order condition of (7) with respect to $\tau$, which is

$$
\tau_{m}=\min \left\{\frac{1+w}{1+\sigma} \frac{\theta-\delta}{1-\delta}, 1\right\}
$$

Let state $S=R$ denote the occurrence of a revolt. The elites are disenfranchised with zero income if this occurs, hence the utility of an elite is $U_{r}(R, \mu)=0$. On the other hand, poor citizens share what remains after a revolt, thus the poor's post-revolutionary income is

$$
\pi_{p}(R, \mu)=\frac{1-\mu}{1-\delta} \bar{y}
$$

and the average income of the nation after a revolt is

$$
\bar{\pi}(R, \mu)=(1-\mu) \bar{y}
$$

Similar to the poor's utility under redistribution, the poor's utility when a revolution occurs under is

$$
U_{p}(R, \mu)=\pi_{p}(R, \mu)+\sigma\left[h_{\sigma}+\bar{\pi}(R, \mu)\right]-w\left\{h_{w}+\left|\pi_{p}(R, \mu)-\bar{\pi}(R, \mu)\right|\right\}
$$

where $\sigma$ and $w$ are as above, and the second term measures the poor's identity utility under a revolt through the nation's average income $\bar{\pi}(R, \mu)$. Substituting (9) and (10) into (11), we find that the poor's post-revolt utility is

$$
U_{p}(R, \mu)=\frac{1-\mu}{1-\delta} \bar{y}+\sigma\left[h_{\sigma}+(1-\mu) \bar{y}\right]-w\left\{h_{w}+\frac{1-\mu}{1-\delta} \delta \bar{y}\right\}
$$

\section{Comparative Statics}

We discuss the conditions under which the elites avert a revolt without the need for redistribution. This occurs when the poor's utility with no taxation outweighs the poor's utility under a revolt, that is $U_{p}(D, 0) \geq U_{p}(R, \mu)$, which occurs when 


$$
\mu \geq \mu_{0}
$$

where

$$
\mu_{0}=\frac{\theta+w(\theta-2 \delta)}{1-w \delta+\sigma(1-\delta)}
$$

Note that the following proposition applies.

Proposition 1 The probability that a revolt never occurs increases in national pride $\sigma$.

Proof: From (13), a revolution never occurs when $\mu \geq \mu_{0}$. Since $\mu \sim U[0,1]$, the probability that a revolt never occurs is $1-\mu_{0}$. However, $\mathrm{d} \mu_{0} / \mathrm{d} \sigma<0$, hence $1-\mu_{0}$ is increasing in $\sigma$ since $\mathrm{d}\left(1-\mu_{0}\right) / \mathrm{d} \sigma=-\mathrm{d} \mu_{0} / \mathrm{d} \sigma>0$. Figure 2 illustrates this phenomenon.

We now derive the condition when a revolt is imminent regardless of the tax rate. This happens when the poor's post-revolutionary utility is greater than the utility under redistribution with tax rate $\tau_{m}$. In other words, a revolt is inevitable if $U_{p}(R, \mu)>U_{p}\left(D, \tau_{m}\right)$ or

$$
\mu<\mu_{m}
$$

where

$$
\begin{aligned}
\mu_{m}= & \frac{1}{1-w \delta+\sigma(1-\delta)}\left\{\theta-\tau_{m}(\theta-\delta)+(1+\sigma)(1-\delta) \frac{\tau_{m}^{2}}{2}\right. \\
& \left.+w\left[\left(1-\tau_{m}\right)(\theta-\delta)-\delta\right]\right\}
\end{aligned}
$$

By the chain rule,

$$
\frac{\mathrm{d} \mu_{m}}{\mathrm{~d} \sigma}=\frac{\partial \mu_{m}}{\partial \tau_{m}} \frac{\mathrm{d} \tau_{m}}{\mathrm{~d} \sigma}+\frac{\partial \mu_{m}}{\partial \sigma}
$$

Since $\partial \mu_{m} / \partial \tau_{m}=0, \theta>\delta$ and $w \in[0,1]$,

$$
\begin{aligned}
\frac{\partial \mu_{m}}{\partial \sigma}= & \frac{-1}{[1-w \delta+\sigma(1-\delta)]^{2}}\left\{\left(1-\tau_{m}\right)[\theta-w \delta]\right. \\
& \left.+w\left(1-\tau_{m}\right)(\theta-\delta)+(1-w)\left[\tau_{m}-\frac{\tau_{m}^{2}}{2}\right] \delta\right\} \\
& <0
\end{aligned}
$$

Hence

$$
\frac{\mathrm{d} \mu_{m}}{\mathrm{~d} \sigma}<0
$$

We state the following result.

Proposition 2 The probability that a revolution is imminent decreases in national pride $\sigma$.

Proof: Inequality (15) informs us that a revolt is imminent when $\mu<\mu_{m}$. As $\mu \sim U[0,1]$, the probability that a revolt is imminent is $\mu_{m}$. Since $\mathrm{d} \mu_{m} / \mathrm{d} \sigma<0$ from (17), we have shown the proposition. See Figure 3. 

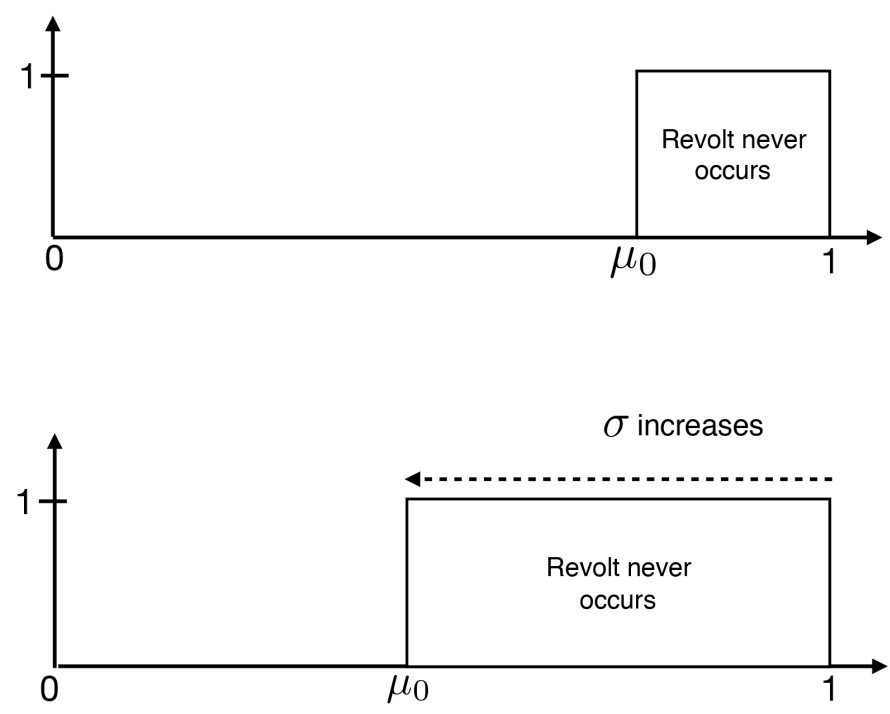

Figure 2. The y-axis represents probability density with respect to $\mu$. As national pride $\sigma$ increases, the probability that a revolt never occur increases.
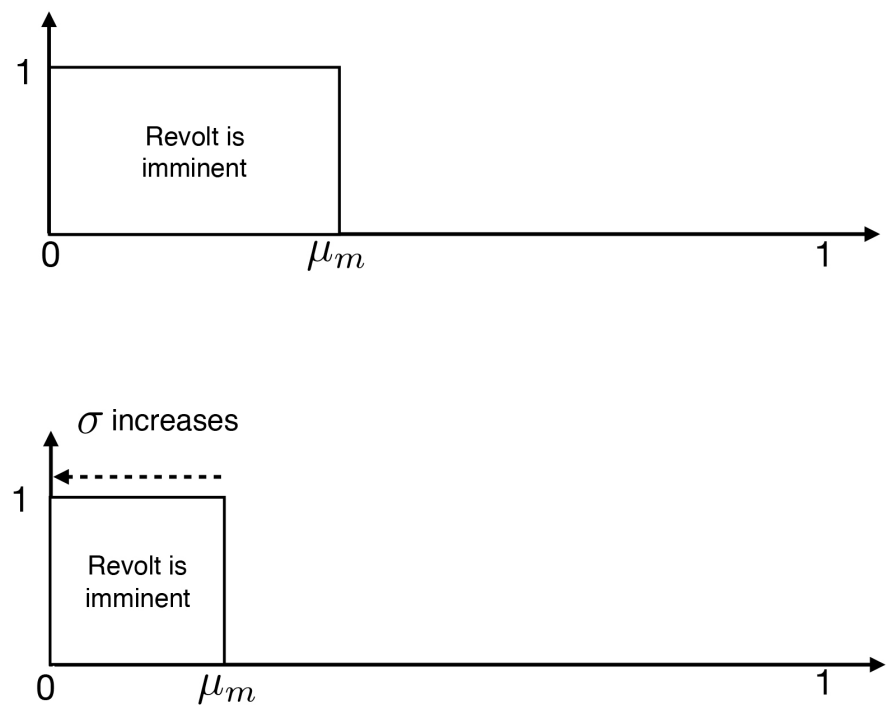

Figure 3. The y-axis represents probability density with respect to $\mu$. As national identification $\sigma$ increases, the probability that a revolt is imminent decreases.

Note the following.

Corollary $1 \mu_{0}>\mu_{m}$.

Proof: Assume on the contrary that $\mu_{0}<\mu_{m}$, and let $\mu$ be such that $\mu_{0}<\mu<\mu_{m}$. By (13) no revolt occurs since $\mu>\mu_{0}$, but (15) stipulates that a revolt is imminent since $\mu<\mu_{m}$. Hence a contradiction. On the other hand, assume that $\mu_{m}=\mu_{0}$, then this implies that $\tau_{m}=0$, which is a contradiction since $\tau_{m}$ either has an interior solution or takes the value 1 by (8).

Having examined the outcomes when $\mu \geq \mu_{0}$ and $\mu<\mu_{m}$, we now describe the outcome when $\mu_{m} \leq \mu<\mu_{0}$, which corresponds to 
$U_{p}(D, 0)<U_{p}(R, \mu) \leq U_{p}\left(D, \tau_{m}\right)$ from (13) and (15). Here a revolt does not occur at a specific level of income redistribution. Since $U_{p}(D, \tau)$ is continuous in $\tau$, the intermediate value theorem stipulates that there exists a $\tau_{\alpha} \in\left[0, \tau_{m}\right]$ that satisfies $U_{p}\left(D, \tau_{\alpha}\right)=U_{p}(R, \mu)$ or

$$
\mu=\mu_{\alpha}\left(\tau_{\alpha}\right)
$$

where

$$
\begin{aligned}
\mu_{\alpha}\left(\tau_{\alpha}\right)= & \frac{1}{1-w \delta+\sigma(1-\delta)}\left\{\theta-\tau_{\alpha}(\theta-\delta)+(1+\sigma)(1-\delta) \frac{\tau_{\alpha}^{2}}{2}\right. \\
& \left.+w\left[\left(1-\tau_{\alpha}\right)(\theta-\delta)-\delta\right]\right\}
\end{aligned}
$$

The following proposition shows that $\tau_{\alpha}$ decreases in national pride $\sigma$, hence the tax rate required to avert a revolt decreases in $\sigma$.

Proposition 3 Let $\mu_{m} \leq \mu<\mu_{0}$ and let $\mu_{\alpha}$ be defined in (19), then there exists $\tau_{\alpha}$ that satisfies $\mu=\mu_{\alpha}\left(\tau_{\alpha}\right)$ such that

$$
\frac{\mathrm{d} \tau_{\alpha}}{\mathrm{d} \sigma}<0
$$

Proof: Let $R\left(\tau_{\alpha}\right)=\mu_{\alpha}\left(\tau_{\alpha}\right)-\mu=0$. Then by the implicit function theorem,

$$
\frac{\mathrm{d} \tau_{\alpha}}{\mathrm{d} \sigma}=-\frac{\partial R / \partial \sigma}{\partial R / \partial \tau_{\alpha}}=-\frac{\partial \mu_{\alpha} / \partial \sigma}{\partial \mu_{\alpha} / \partial \tau_{\alpha}}
$$

Since $w \in[0,1]$ and by the definition of $\mu_{\alpha}\left(\tau_{\alpha}\right)$ (19),

$$
\begin{aligned}
\frac{\partial \mu_{\alpha}}{\partial \sigma}= & \frac{-1}{[1-w \delta+\sigma(1-\delta)]^{2}}\left\{\left(1-\tau_{\alpha}\right)[\theta-w \delta]\right. \\
& \left.+w\left(1-\tau_{\alpha}\right)(\theta-\delta)+(1-w)\left(\tau_{\alpha}-\frac{\tau_{\alpha}^{2}}{2}\right) \delta\right\} \\
& <0
\end{aligned}
$$

Because $\tau_{\alpha}<\tau_{m}$,

$$
\frac{\partial \mu_{\alpha}}{\partial \tau_{\alpha}}=\frac{-(1+w)(\theta-\delta)+(1+\sigma)(1-\delta) \tau_{\alpha}}{1+\sigma(1-\delta)-w_{y} \delta}<0
$$

Thus $\mathrm{d} \tau_{\alpha} / \mathrm{d} \sigma<0$, which proves the proposition.

We state the subgame perfect equilibrium of the game below.

Proposition 4 Let $\sigma, w \in[0,1], \mu \sim U[0,1]$ and $\mu_{0}, \mu_{m}, \mu_{\alpha}$ be defined in (14), (16) and (19). Then there is a unique subgame perfect equilibrium $\left\{\tilde{\omega}_{p}, \tilde{\omega}_{r}\right\}$ in the game described in Figure 1 such that if

1) $\mu \geq \mu_{0}$, citizens will never revolt and elites set a flat tax $\hat{\tau}=0$.

2) $\mu<\mu_{m}$, a revolt is imminent for any $\hat{\tau} \in[0,1]$.

3) $\mu_{m} \leq \mu<\mu_{0}$, the elites implement $\hat{\tau}=\tau_{\alpha}$ and citizens do not revolt.

Proof: Refer to (13), (15) and (19).

Proposition 4 highlights the way in which non-democracy equilibrium policies are determined by both the preferences of elites and the constraints they face from citizens. When such constraints are absent as in scenario 1) above, only the 
policy preference of the elites matter. When such constraints are present, as in scenario 2) and 3), the elites are constrained by the preference for revolt by the poor and can manipulate the utility of the poor through income redistribution and increasing nationalism.

\section{Method and Data}

We investigate two theoretical results using statistical analysis. The first is Proposition 2, which shows that national pride has a negative impact on the poor's likelihood of revolt. The second is Proposition 3, which demonstrates that the required tax rate to avert a revolt decreases in national pride. Note that the methodology we employ is similar that in MacCulloch (2004, 2005), which examines the impact of inequality on respondent's "taste" for revolt.

We use integrated cross-sectional data from the World Value Survey (WVS) from 1981 to 2014. Note that all model specifications include country dummies to account for country-specific traits, and year dummies to capture common shocks for all countries. We restrict our analysis to "poor" individuals, which are respondents from the 1st to 5th decile on the "scale of income" variable in the. In the integrated survey, the 1st decile is the lowest income group and the 10th decile is the highest. Furthermore, robust standard errors clustered by country are present to account for arbitrary heteroskedasticity and serial correlation at the country level.

Ideally, we would test Proposition 1 using methods employed in the analysis of panel data. However, since observations (interviewees) differ from one wave of the survey to another, we employ methods used to analyze cross-sectional data instead. In particular, we statistically verify Proposition 1 by applying logit regression analysis to the following.

$$
\begin{aligned}
\text { Revolt }_{i c t}= & \beta_{h 0}+\beta_{h 1} \text { National Pride }_{i c t}+\beta_{h 2} \text { Non-democracy }_{c t} \\
& +\beta_{h 3} \text { National Pride }_{i c t} \times \text { Non-democracy }_{c t} \\
& +\beta_{h 4} \text { Personal Characteristics }_{i c t} \\
& +\beta_{h 5} \text { Macro Controls }_{i c t}+\text { Country }_{c}+\text { Year }_{t}+\varepsilon_{i c t}
\end{aligned}
$$

Revolt $_{i c t}$ is a dummy variable that is constructed from the WVS variable: "On this card are three basic kinds of attitudes vis-a-vis the society in which we live. Please choose the one which best describes your own opinion." The responses are 1) The entire way our society is organized must be radically changed by revolutionary action 2) Our society must be gradually improved by reforms 3 ) Our present society must be valiantly defended against all subversive forces. We code response 1) with 1 to indicate respondent willingness to revolt and 0 otherwise.

National pride ${ }_{i c t}$ is a dummy created from the WVS question: "How proud are you to be [e.g. French]?" with a scale from 1 to 4 ("very proud," "quite proud," "not very proud," and "not at all proud"). We code 1 for "very proud" and "quite proud", while all other entries are coded as 0 to create a binary variable for national pride. We also include the interaction term National Pride $_{i c t} \times$ 
Non-democracy $c_{c t}$ to investigate whether individuals who are proud of the nation in non-democracies are less likely to revolt against the regime. The classification of non-democracy is based on the Boix-Miller-Rosato Dichotomous Coding of Democracy 1800-2010.

Personal Characteristics $i c t$ is a vector of controls at the level of the individual. It includes age, age ${ }^{2}$, gender, employment status ("full time", "Part time", "self-employed", "retired", "housewife", "student", "Unemployed", "Other"), marital status ("single", "married", “divorced”, "separated”, “widowed”). We also include the age when respondents completed formal schooling ("below fifteen", "fifteen to seventeen", "above seventeen”), respondent's number of children ("no child", "one child", "two children", "three and more"), and a dummy on whether respondents are religious ("a religious person", "not a religious person" and "a convinced atheist"). Macro Controls $c$ refers to a set of country-level variables, which are real GDP per capita from the Expanded Trade and GDP database by Kristian Gleditsch, gini index from The Standardized World Income Inequality Database (SWIID), as well as unemployment and inflation rates using data from the World Bank.

To examine Proposition 3, we not only restrict our analysis to respondents whose income scale is at the 5th decile and below (similar to our empirical strategy of verifying Proposition 1), but also limit our analysis to individuals who display revolutionary tendencies by stating "the entire way our society is organized must be radically changed by revolutionary action". We estimate the following regression using OLS.

$$
\begin{aligned}
\text { Income difference }_{i c t}= & \beta_{g 0}+\beta_{g 1} \text { National Pride }_{i c t}+\beta_{g 2} \text { Non-democracy }_{c t} \\
& +\beta_{g 3} \text { National Pride }_{i c t} \times \text { Non-democracy }_{c t} \\
& +\beta_{g 4} \text { Personal Characteristics } \\
& +\beta_{g 5} \text { Macro Controls }_{i c t}+\text { Country }_{c}+\text { Year }_{t}+\gamma_{i c t}
\end{aligned}
$$

Our dependent variable from the WVS rates respondent stated preference for larger income differences. With a scale from 1 to 10, individuals that score 1 state that "incomes should be made more equal" and respondents that score 10 claim that "we need larger income differences as incentives for individual effort". The main independent variable is national pride discussed above, and just like our empirical strategy in estimating (21), we control for level of democracy and include an interaction term for national pride and non-democracy to account for the impact of national pride in favoring lower levels of income redistribution (higher income differences) in non-democracies. The set of personal characteristics and macroeconomic controls are the same as those in (21).

\section{Empirical Results}

The first two columns in Table 1 use logit regression analysis to investigate the impact of national pride on the likelihood that individuals would claim that there is a need for revolutionary action. 
Table 1. We apply logit regression analysis in columns 1 and 2, and OLS in columns 3 and 4. Data are from the World Value Survey, and include survey data from respondents in 4 waves from 1981 to 2004 . Robust standard errors clustered by countries are in parentheses, and all specifications include country and year dummies. The dependent variable "must radically change society" is a dichotomous variable that equals one when respondents state that "society should be changed in a radical manner" and those that say otherwise are coded zero. National pride is a dummy created from the WVS question: "How proud are you to be [e.g. French]?" with a scale from 1 to 4 ("very proud," "quite proud," "not very proud," and "not at all proud"). We construct a binary main independent variable by coding 1 for "very proud" and 0 otherwise. The classification of non-democracy is based on the Boix-Miller-Rosato Dichotomous Coding of Democracy 1800-2010. Micro-level controls such as respondent's income quintile, age, age ${ }^{2}$, gender, employment status, marital status, age when respondent finished formal schooling, number of children and whether respondent belongs to any religious denomination. Additionally, macroeconomic controls such as GDP per capita, gini index, inflation and unemployment rate are present.

\begin{tabular}{ccccc}
\hline Dependent variable & \multicolumn{2}{c}{ Society must be radically changed } & \multicolumn{2}{c}{ Greater Income Differences } \\
\hline & $(1)$ & $(2)$ & $(3)$ & $(4)$ \\
\hline \multirow{2}{*}{ Very proud of nation } & $-0.281^{\star * \star}$ & $-0.255^{\star * *}$ & $0.355^{\star *}$ & $0.372^{\star *}$ \\
& $(0.066)$ & $(0.066)$ & $(0.105)$ & $(0.122)$ \\
Non-democracy & $0.316^{*}$ & $0.408^{\star}$ & -0.722 & $-1.262^{\star * *}$ \\
& $(0.123)$ & $(0.194)$ & $(0.457)$ & $(0.185)$ \\
Very proud of nation $\times$ & -0.044 & -0.052 & -0.017 & -0.233 \\
Non-Democracy & $(0.091)$ & $(0.140)$ & $(0.178)$ & $(0.211)$ \\
Countries & 57 & 44 & 54 & 41 \\
Observations & 61,432 & 42,077 & 7140 & 4400 \\
Personal characteristic & No & Yes & No & Yes \\
Macro controls & No & Yes & No & Yes \\
Log-likelihood & $-21,752.38$ & $-13,716.53$ & -3170.46 & -1852.41 \\
Pseudo $R^{2}$ & 0.06 & 0.07 & 0.06 & 0.06 \\
\hline
\end{tabular}

Analysis in column 1 excludes personal characteristics and macroeconomic controls and show that the national pride variable is significant at the $0.1 \%$ level. Respondents within non-democracies who profess to be very proud of the nation are $24 \%$ less likely to claim that revolutionary action should be taken than those that claim otherwise $\left(1-\mathrm{e}^{-0.281} \approx 0.24\right)$. Column 2 demonstrates that with the inclusion of personal characteristics and macroeconomic controls, national pride is positive and significant at the level of $0.1 \%$, and respondents in non-democracies that are very proud of the nation are $23 \%$ less likely to have a stated preference for revolt compared to those who are not very proud of the nation.

Column 3 and 4 examine the way in which national pride impacts the stated preference for levels of income distribution in non-democracies for agents who believe society should be changed through revolutionary action. In column 3, we perform the regression in the absence of personal characteristics and macroeconomic controls. Accordingly, the coefficient for national pride is 0.355 , which is 
statistically significant at the level of $1 \%$. Hence, an individual who is a member of a non-democracy who wishes to change society in a revolutionary way is $43 \%$ more likely to ask for lower levels of redistribution if that person is very proud of the nation $\left(1-\mathrm{e}^{0.355} \approx 0.43\right)$. In column 4 , national pride is significant at the level of $1 \%$, and the coefficient is 0.372 . Thus, among poor respondents who have a stated preference for revolutionary action, those who are very proud of the nation are $45 \%$ more likely to ask for greater income differences than those who are not very proud of their nation.

\section{Conclusions}

Non-democracies often use nationalism to garner domestic support to remain in power. We demonstrate the feasibility of this phenomenon by showing game theoretically that increasing national pride increases the probability that a revolt never occurs, decreases the likelihood that a revolt is imminent and shows that the tax rate needed to avert a revolt decreases in national pride. We find empirical support for these results by applying logit regression analysis on integrated World Value Survey data from 1981 to 2014.

In terms of policy, governments in non-democracies should raise levels of national pride or identity to consolidate their hold onto power. This is possible through nation-building programs at the school level such as highlighting the contributions and sacrifices of national icons and what they strived to achieve in the process of nation-building.

\section{Acknowledgements}

Sincere thanks go to colleagues in the Nottingham University Business School at Malaysia for their support on this project and the anonymous reviewer for valuable feedback.

\section{Conflicts of Interest}

The authors declare no conflicts of interest regarding the publication of this paper.

\section{References}

[1] Byman, D. and Lind, J. (2010) Pyongyang's Survival Strategy: Tools of Authoritarian Control in North Korea. International Security, 35, 44-74. https://doi.org/10.1162/ISEC_a_00002

[2] Hobwsbawn, E. (1990) Nation and Nationalism since 1780. Cambridge University Press, Cambridge.

[3] Bellin, E. (2012) Reconsidering the Robustness of Authoritarianism in the Middle East: Lessons from the Arab Spring. Comparative Politics, 44, 127-149. https://doi.org/10.5129/001041512798838021

[4] Akerlof, G. and Kranton, R. (2006) Identity and the Economics of Organization. Journal of Economic Perspectives, 19, 9-32. https://doi.org/10.1257/0895330053147930 
[5] Acemoglu, D. and Robinson, J. (2006) Economic Origins of Dictatorship and Democracy. Cambridge University Press, Cambridge.

[6] Wintrobe, R. (1990) The Tinpot and the Totalitarian: An Economic Theory of Dictatorship. American Political Science Review, 84, 849-872. https://doi.org/10.2307/1962769

[7] Wintrobe, R. (1998) The Political Economy of Dictatorship. Cambridge University Press, Cambridge. https://doi.org/10.1017/CBO9781139174916

[8] Alesina, A. and Reich, B. (2015) Nation-Building. Mimeo.

[9] Gellner, E. (1983) Nations and Nationalism. Blackwell, Oxford.

[10] Lott Jr., J.R. (1999) Public Schooling, Indoctrination, and Totalitarianism. Journal of Political Economy, 107, 127-157. https://doi.org/10.1086/250106

[11] Kymlicka, W. (2001) Politics in the Vernacular: Nationalism, Multiculturalism, and Citizenship. Oxford University Press, Oxford. https://doi.org/10.1093/0199240981.001.0001

[12] Acemoglu, D., Ticchi, D. and Vindigni, A. (2010) A Theory of Military Dictatorships. American Economic Journal: Macroeconomics, 2, 1-42. https://doi.org/10.1257/mac.2.1.1

[13] Bolton, P. and Roland, G. (1997) The Breakup of Nations: A Political Economy Analysis. Quarterly Journal of Economics, 112, 1057-1090. https://doi.org/10.1162/003355300555420

[14] Shayo, M. (2009) A Model of Social Identity with an Application to Political Economy: Nation, Class, and Redistribution. The American Political Science Review, 103, 147-174. https://doi.org/10.1017/S0003055409090194

[15] Sambanis, N. and Shayo, M. (2013) Social Identification and Ethnic Conflict. The American Political Science Review, 107, 294-325. https://doi.org/10.1017/S0003055413000038

[16] Tan, C.M., Lee, Y.H. and Ng, P.K. (2018) National Identity and Social Welfare. Theoretical Economics Letters, 8, 1665-1673.

https://doi.org/10.4236/tel.2018.810107 


\section{Appendix}

Table A1. Summary statistics.

\begin{tabular}{|c|c|c|}
\hline Categorical Variable & Observations & Percentage \\
\hline \multicolumn{3}{|l|}{ Basic attitude towards society: } \\
\hline Society should be radically changed & 13,408 & 12.20 \\
\hline Society should be gradually reformed & 77,389 & 70.20 \\
\hline Society should be valiantly defend & 19,425 & 17.60 \\
\hline \multicolumn{3}{|l|}{ Proud of nation: } \\
\hline Not at all proud & 6252 & 2.20 \\
\hline Not very proud & 22,954 & 8.09 \\
\hline quite proud & 84,244 & 29.70 \\
\hline very proud & 170,172 & 60.00 \\
\hline \multicolumn{3}{|l|}{ Regime type: } \\
\hline Democracy & 138,450 & 70.27 \\
\hline non-democracy & 58,566 & 29.73 \\
\hline \multicolumn{3}{|l|}{ Gender: } \\
\hline Female & 144,678 & 51.04 \\
\hline Male & 138,790 & 48.96 \\
\hline \multicolumn{3}{|l|}{ Employment status: } \\
\hline Full-time & 95,752 & 33.76 \\
\hline Part-time & 23,011 & 8.11 \\
\hline Self-employed & 30,054 & 10.60 \\
\hline Retired & 32,707 & 11.53 \\
\hline Housewife & 39,251 & 13.84 \\
\hline Students & 21,826 & 7.70 \\
\hline Unemployed & 5034 & 1.77 \\
\hline \multicolumn{3}{|l|}{ Marital status: } \\
\hline Married & 158,876 & 56.02 \\
\hline Living together as married & 18,219 & 6.42 \\
\hline Divorced & 9525 & 3.36 \\
\hline Separated & 4987 & 1.76 \\
\hline Widowed & 15,675 & 5.53 \\
\hline Single/Never Married & 72,738 & 25.65 \\
\hline Divorced, separated or widowed & 83 & 0.03 \\
\hline \multicolumn{3}{|l|}{ Age when schooling is completed: } \\
\hline Finish education before 15 & 37,928 & 13.00 \\
\hline Finish education between 15 and 17 & 46,500 & 16.40 \\
\hline Finish education at 18 or above & 199,194 & 70.23 \\
\hline
\end{tabular}




\section{Continued}

\begin{tabular}{ccc}
\hline Number of children: & & \\
\hline No children & 80,508 & 28.39 \\
One child & 43,458 & 15.32 \\
Two children & 69,015 & 24.33 \\
three or more children & 90,641 & 31.96 \\
\hline Religious level: & & \\
\hline A religious person & 12,208 & 4.65 \\
Not a religious person & 64,308 & 24.47 \\
A convinced atheist & 186,259 & 70.88 \\
\hline
\end{tabular}

Table A2. Descriptive statistics, 1981 to 2014.

\begin{tabular}{cccccc}
\hline Continuous Variable & Obs & Mean & Std. Dev. & Min. & Max \\
\hline Real GDP per capita & 222,518 & $12,676.96$ & $12,757.49$ & 330.38 & $97,904.79$ \\
Gini index & 234,003 & 37.89 & 8.65 & 21.38 & 58.02 \\
Inflation rate & 264,436 & 19.16 & 74.97 & -2.42 & 1058.37 \\
Unemployment rate & 227,166 & 9.12 & 6.15 & 0.40 & 34.50 \\
\hline
\end{tabular}

